\title{
Changes in expression of p53 and inflammatory factors in patients with ulcerative colitis
}

\author{
HUI SU, QIAN KANG, HAIHONG WANG, HUI YIN, LINGHUI DUAN, YULI LIU and RUYING FAN \\ Department of Gastroenterology, PLA Army General Hospital, Beijing 100700, P.R. China
}

Received May 16, 2018; Accepted November 19, 2018

DOI: $10.3892 /$ etm.2019.7253

\begin{abstract}
Ulcerative colitis (UC) is an important risk factor for the occurrence of colon cancer, and changes in expression of p53 and inflammatory factors are closely related to the pathogenesis of colon cancer. Therefore, changes in expression of p53 and inflammatory factors in UC were investigated to explore its intrinsic pathogenetic laws. The levels of inflammatory factors, such as interleukin-6 (IL-6), tumor necrosis factor- $\alpha$ (TNF- $\alpha)$, IL-10 and IL-4, in peripheral blood of UC patients and healthy adults were detected via enzyme-linked immunosorbent assay, and the changes in p53 expression were analyzed via immunohistochemistry and western blotting, and the correlation of p53 expression with changes in cytokines was also analyzed. Moreover, changes in $45 \mathrm{~S}$ preribosomal ribonucleic acid (preRNA) transcriptional activity in four kinds of cell lines exposed to IL-6 were analyzed and determined by using reverse transcription-quantitative polymerase chain reaction. Finally, the $\mathrm{C}$-myc protein expression after IL-6 stimulation was analyzed and evaluated via western blot analysis. The levels of IL- 6 and TNF- $\alpha$ in peripheral blood in the UC patient group were significantly increased compared with those in the healthy adult group $(\mathrm{P}<0.01)$, while the levels of IL-10 and IL-4 in peripheral blood were significantly decreased compared with those in the healthy adult group $(\mathrm{P}<0.01)$. The $\mathrm{p} 53$ expression had a significant negative correlation with IL-6. The results showed that IL-6 activated C-myc messenger RNA (mRNA) translation, thereby upregulating the ribosomal RNA (rRNA) transcription. Additionally, IL-6 stimulated the mouse double minute 2 homolog (MDM2)mediated proteasomal degradation of p53 by reducing the availability of ribosomal protein used for MDM2 binding, thus resulting in the downregulation of $\mathrm{p} 53$ protein expression. The findings of the study show that, expression level of IL-6 was increased in UC patients, which regulates the downregulation
\end{abstract}

Correspondence to: Dr Ruying Fan, Department of Gastroenterology, PLA Army General Hospital, 5 Nanmencang, Beijing 100700, P.R. China

E-mail: scorpio81@sina.com

Key words: ulcerative colitis, p53, inflammatory factors, IL-6, correlation of p53 expression level and plays a role in tumorigenesis through enhancing cell proliferation and inhibiting apoptosis.

\section{Introduction}

Ulcerative colitis (UC) is a definite risk factor for the development of many colon cancers $(1,2)$. Inflammatory substances released from the inflamed tissue can promote the tumor growth by inducing oncogene deoxyribonucleic acid (DNA) replication or reducing tumor suppressor genes, and increase the mutant cell proliferation $(3,4)$. Among various substances in the inflammatory environment, changes in inflammatory factors have significant differences, which are the most obvious in inflammatory factors, such as interleukin-6 (IL-6), tumor necrosis factor- $\alpha$ (TNF- $\alpha$ ), IL-10 and IL-4 in related cancers. It is reported in the literature that IL- 6 has been proven to play a basic role in experimental colitis, and high-level IL-6 is a major risk factor for the development of human colorectal tumor and hepatocellular carcinoma (5). Such a close relationship between IL-6 and cancer suggests that the effects of IL-6 on promoting cell proliferation and reducing apoptosis may not be the only tumor-inducing mechanism controlled by cytokines, but it should be assumed that the additional IL-6 effect may lead to tumorigenesis.

Recent studies have demonstrated that IL-6 downregulates the p53 expression and activity through stimulation of the upregulation of ribosomal ribonucleic acid (rRNA) transcription in proliferation factors and enhancing mouse double minute 2 homolog (MDM2)-mediated p53 proteasome digestion. It is hypothesized that stimulating factors of cell proliferation are produced under pathological conditions of human body, such as chronic inflammatory process, and the similar mechanism may be positive, thus contributing to tumor transformation. In this study, therefore, whether IL-6 could stimulate rRNA transcription and downregulate p53 transcription and p53 expression and activity in untransformed cell lines was investigated first. It was found that IL-6 enhanced the rRNA transcription, and reduced p53 expression and function through activation of ribonucleoprotein-MDM2 degradation pathway of p53 and upregulating rRNA synthesis. In addition, it was observed that p53 downregulation leads to epithelial-mesenchymal transition (EMT) characterized by phenotypic and functional changes in cells exposed to IL-6. Considering that the onset of colon cancer in UC patients is a highly representative example of the occurrence of chronic 
inflammation-related tumors (6), whether changes induced by IL- 6 in human cell lines also existed in chronic ulcerative colonic mucosa in human epithelial cells was studied.

The results revealed that there was significant nucleolus hypertrophy (a morphological marker of rRNA upregulation) in epithelial cells of all UC cases examined (7), and the p53 immunostaining was decreased. Moreover, major EMT phenotypic changes and decreased E-cadherin expression could also be seen in epithelial cells in colonic mucosa in UC patients. These data provide a new pathway of IL-6-induced stimulation of rRNA transcription, and link inflammation to cancer.

\section{Materials and methods}

Patient data. A total of 25 UC patients, including 14 males and 11 females, aged $49.8 \pm 10.3$ years on average, and 25 healthy subjects, including 12 males and 13 females, aged $45.6 \pm 9.6$ years on average, were enrolled in this study. After routine clinical nursing and monitoring were conducted, and informed consent was obtained, biopsy specimens were obtained via colonoscopy. The diagnosis of UC was based on the routine clinical, endoscopic and histopathological criteria described by Lennard-Jones (8). The biopsy tissues of patients without gross lesions or history of any gastrointestinal disease were used as the control group. The patients had suffered from UC for $>5$ years. In all UC cases, the specimens were obtained from the transverse colon and ascending colon. All the UC patients underwent initial colonoscopy during the active disease and then received a second endoscopy during the clinical remission which was confirmed histologically. The specimens collected were fixed in formalin and embedded in paraffin for histological examination. The study was approved by the Ethics Committee of PLA Army General Hospital (Beijing, China).

Cell lines and chemotherapy. HepG2, SW1990 and LS174T cell lines were obtained from the China Center for Type Culture Collection (Wuhan, China), and the NCM460 cell line was purchased from INCELL Corporation (San Antonio, TX, USA). All cell lines were p53 wild-type. The HCT116 p53 ${ }^{-1}$ cell line was generously donated by Professor Bert Vogelstein.

Experimental materials. Cytokine enzyme-linked immunosorbent assay (ELISA) kit (Genzyme, Cambridge, MA, USA), recombinant human IL-6 at a final concentration of $50 \mathrm{ng} / \mathrm{ml}$ (Sigma-Aldrich, Milan, Italy), proteasome inhibitor MG-132 at a final concentration of $10 \mathrm{mM}$ (Calbiochem; Merck Chemicals Ltd., Nottingham, UK), cycloheximide at a final concentration of $20 \mu \mathrm{g} / \mathrm{ml}$ (Sigma-Aldrich; Merck KGaA, Darmstadt, Germany), hydroxyurea (Sigma-Aldrich; Merck KGaA), 5-FU (Fluorouracil; Teva Pharma Italia, Milan, Italy), Nutlin-3 (Sigma-Aldrich; Merck KGaA), anti-E-cadherin (clone 32A8, Cell Signaling Technology, Inc., Danvers, MA, USA), antiIL-6 (Sigma-Aldrich; Merck KGaA), anti-p53 (Novocastra, Laboratories, Ltd., Newcastle upon Tyne, UK), and p53 Taqman gene expression quantitative assay kit (Applied Biosystems, Foster City, CA, USA) were used in the present study.

Immunohistochemical evaluation. Antigens in tissue sections were displayed by using the non-biotin amplification method.
The sections were then incubated with primary anti-human p53 monoclonal antibody (1:200; cat. no. 2527, Cell Signaling Technology, Inc.) diluted with $1 \%$ bovine serum albumin in Tris-buffer at $4^{\circ} \mathrm{C}$ overnight. The sections were counterstained with hematoxylin, and dehydrated and covered with the cover glass. The nuclear p53 immunostaining was evaluated via image cytometry by using the Cytometrica program. According to the study of Faccioli et al (9), staining in the section labeling index was presented as the percentage of the labeled nuclear area in the total nuclear area of epithelial cells.

Detection of cytokine levels (IL-6, TNF- $\alpha, I L-10$ and IL-4) in human peripheral blood via ELISA. After $5 \mathrm{ml}$ peripheral venous blood was drawn from patients and anti-coagulated with ethylene diamine tetraacetic acid (EDTA), and the serum was isolated and stored in a refrigerator at $-70^{\circ} \mathrm{C}$ to be detected. The pro-inflammatory factors (IL-6, TNF- $\alpha$, IL-10 and IL-4) (cat. nos. KE00007, 17590-1-AP, KE00012, KE00016, respectively; ProteinTech Group, Inc.; Wuhan, China) in serum of patients were detected via ELISA.

Taqman fluorescence quantitative polymerase chain reaction (PCR). Total RNA was extracted using TRIzol reagent, and the whole cell RNA was quantified via spectrophotometry (Bio-Rad Laboratories, Inc., Hercules, CA, USA). RNA (2 $\mu \mathrm{g})$ was reversely transcribed using a high-capacity complementary DNA (cDNA) reverse transcription kit according to the manufacturer's protocol. Quantiative PCR was performed on ABI Prism 7000 instrument, and the average $\Delta \mathrm{Cq}$ value of control specimens was used in each experiment to calculate the replicated $\Delta \Delta \mathrm{Cq}$ value of specimens (10). Primers and probes were selected by using the Roche online primer design tool, and primers used for Taqman real-time PCR analysis of human PUMA and p53 were designed.p53 and C-myc were quantitatively detected by using the Taqman gene expression assay primer and probe kits (11). p53: Forward, GACGGTGACACGCTTCCCTGGATT; reverse, GGGAACAAGAAGTGGAGAATGTCA; c-MYC: Forward, GAGAGGCAGAGGGAGCGAGCGGGC; reverse, TGTCGTTGAGAGGGTAGGGGAAGA.

Isolation of polysome messenger RNA (mRNA). Cells were washed in phosphate-buffered saline (PBS) at $4^{\circ} \mathrm{C}$, and the cell sediment was lysed in $10 \mathrm{mmol} / \mathrm{l}$ Tris- $\mathrm{HCl}$ (pH 7.4), $10 \mathrm{mmol} / \mathrm{l}$ $\mathrm{NaCl}, 3 \mathrm{mmol} / 1 \mathrm{MgCl}_{2}$ and $0.5 \% \mathrm{NP} 40$ at $4^{\circ} \mathrm{C}$ for $10 \mathrm{~min}$. The lysate was centrifuged at $14,000 \mathrm{x} \mathrm{g}$ at $4^{\circ} \mathrm{C}$ for $10 \mathrm{~min}$, and the polysome was isolated from supernatant. The lysate was layered into $15-50 \%$ sucrose gradient by using $30 \mathrm{mmol} / 1$ HEPES/KOH (pH 7.5), $80 \mathrm{mmol} / 1 \mathrm{KCl}$ and $1.8 \mathrm{mmol} / 1$ $\mathrm{Mg}$-acetate, followed by centrifugation at $14,000 \mathrm{x}$ g at $4^{\circ} \mathrm{C}$ for $15 \mathrm{~h}$. Then, $1 \mathrm{ml}$ lysate was collected from each gradient, and the absorbance was read at $260 \mathrm{~nm}$ on a microplate reader (Bio-Rad Laboratories, Inc.). The polyribosome was integrated and centrifuged at $100,000 \times \mathrm{g}$ and $4^{\circ} \mathrm{C}$ for $15 \mathrm{~h}$, and RNA was extracted using TRIzol reagent.

Western blot analysis. Whole cell protein extraction, and subsequent sodium dodecyl sulfate-polyacrylamide gel electrophoresis and western blot analysis were performed as previously described (12). Briefly, the total cell protein was extracted in lysis buffer $\left[\mathrm{KH}_{2} \mathrm{PO}_{4} 0.1 \mathrm{MpH} 7.5, \mathrm{NP}-401 \%\right.$, added 

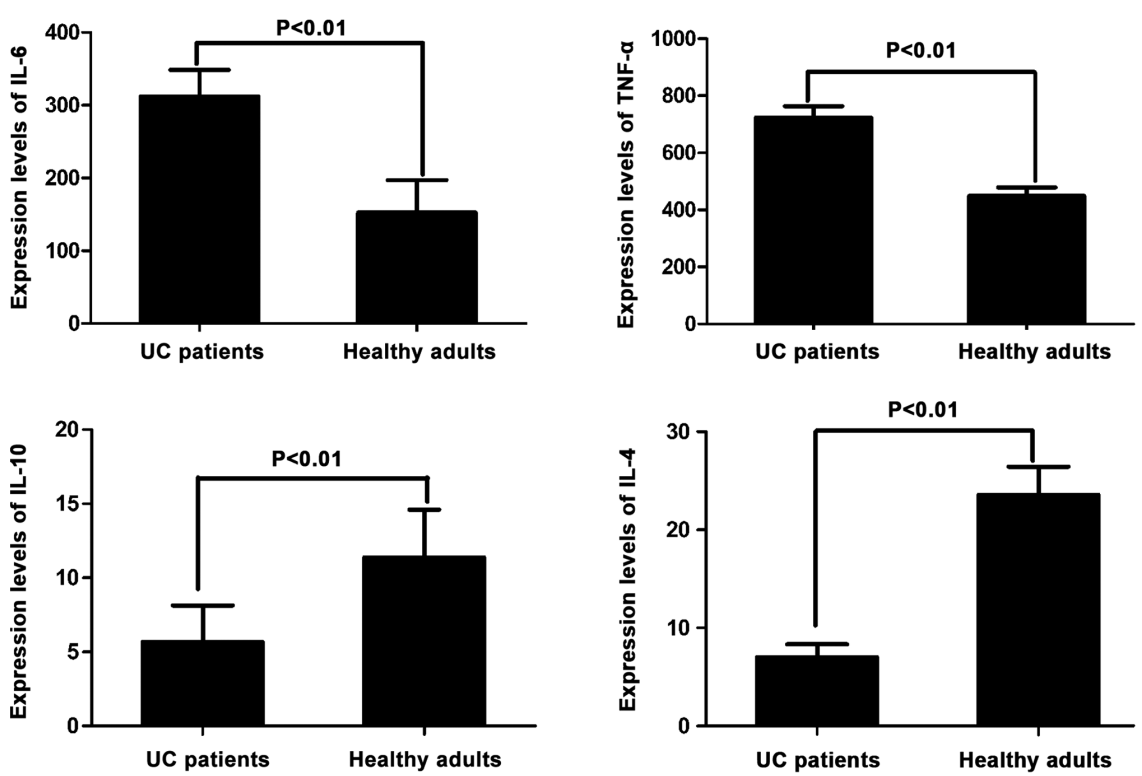

Figure 1. Expression levels of inflammatory factors (IL-6, TNF- $\alpha$, IL-10 and IL-4) in peripheral blood of UC patients. The differences in expression is significant compared with that in healthy adults $(\mathrm{P}<0.01), \mathrm{n}=25$. IL-6, interleukin-6; TNF- $\alpha$, tumor necrosis factor- $\alpha$; UC, ulcerative colitis.

with complete protease inhibitor cocktail (Roche Diagnostics, Basel, Switzerland) and $0.1 \mathrm{mM} \beta$-glycerophosphate], and detected via Bio-Rad protein assay. Nucleoprotein used for western blot analysis was obtained. After being fixed on the nitrocellulose membrane, the protein was incubated with the primary mouse anti-human c-myc, p53, $\beta$-actin monoclonal antibodies (1:500; cat. nos. sc-42, sc-81168 and sc-70319, respectively) [Santa Cruz Biotechnology, Inc. (Dallas, TX, USA)] at $4^{\circ} \mathrm{C}$ overnight. Horseradish peroxidase-conjugated secondary goat anti-mouse IgG-HRP polyclonal antibody (1:1,000; cat. no. sc-2005) was purchased from Santa Cruz Biotechnology, Inc. The densitometry was analyzed using Image J (National Institutes of Health, Bethesda, MD, USA).

mRNA transfection. The capped mRNA was transcribed in the linearized pR-C-myc-IRES-F (donated by Professor R.J. Schneider) and the control pRF plasmid by using the mMessage mMachine T3 kit (Ambion; Thermo Fisher Scientific, Inc., Waltham, MA, USA). According to the manufacturer's instructions, cells were transfected with $0.4 \mu \mathrm{g}$ RNA in each specimen by using Lipofectamine 2000 (Invitrogen; Thermo Fisher Scientific, Inc.). After transfection for $8 \mathrm{~h}$, the cells were collected and analyzed by using the dual-luciferase assay kit (Promega Corporation, Madison, WI, USA) in accordance with the manufacturer's protocol.

Statistical analysis. Chi-square test or Mann-Whitney U test was used for the intergroup comparison if appropriate. The consistency among scores was evaluated via K statistics. Statistical Product and Service Solutions (SPSS) software package was used for all statistical data. $\mathrm{P}<0.05$ was considered to indicate a statistically significant difference.

\section{Results}

Detection of changes in inflammatory factors via ELISA. The level of IL-6 in 25 patients with UC $(312.16 \pm 36.34 \mathrm{ng} / \mathrm{l})$

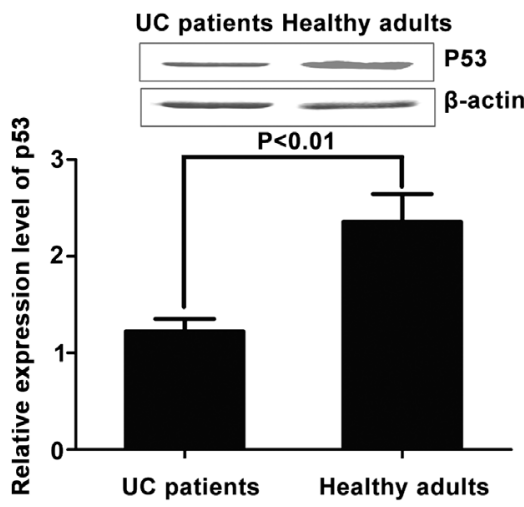

Figure 2. Relative expression level of p53 in peripheral blood of UC patients. Results of quantitative PCR and western analysis show that the expression level of p53 in peripheral blood of UC patients is significantly decreased compared with that in healthy adults $(\mathrm{P}<0.01), \mathrm{n}=25$. UC, ulcerative colitis

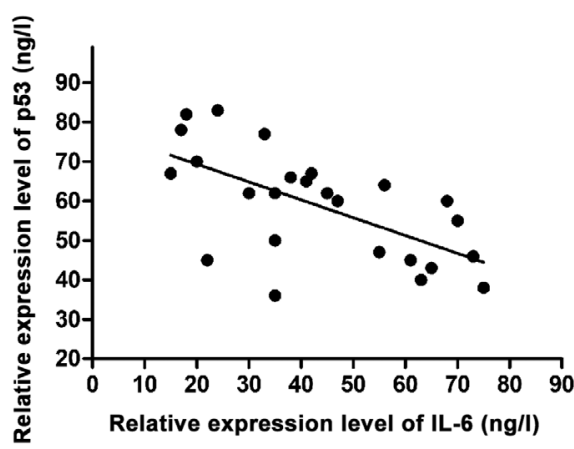

Figure 3. Correlation analysis of IL-6 and p53 expression. Results of linear correlation analysis reveal that the relative expression level of p53 is decreased with the increase of relative expression level of IL-6 $(\mathrm{P}<0.001)$, $\mathrm{n}=25$. IL-6, interleukin-6.

was significantly higher than that in healthy adult controls $(152.66 \pm 44.42 \mathrm{ng} / \mathrm{l})$, which was nearly 2 -fold higher than that 

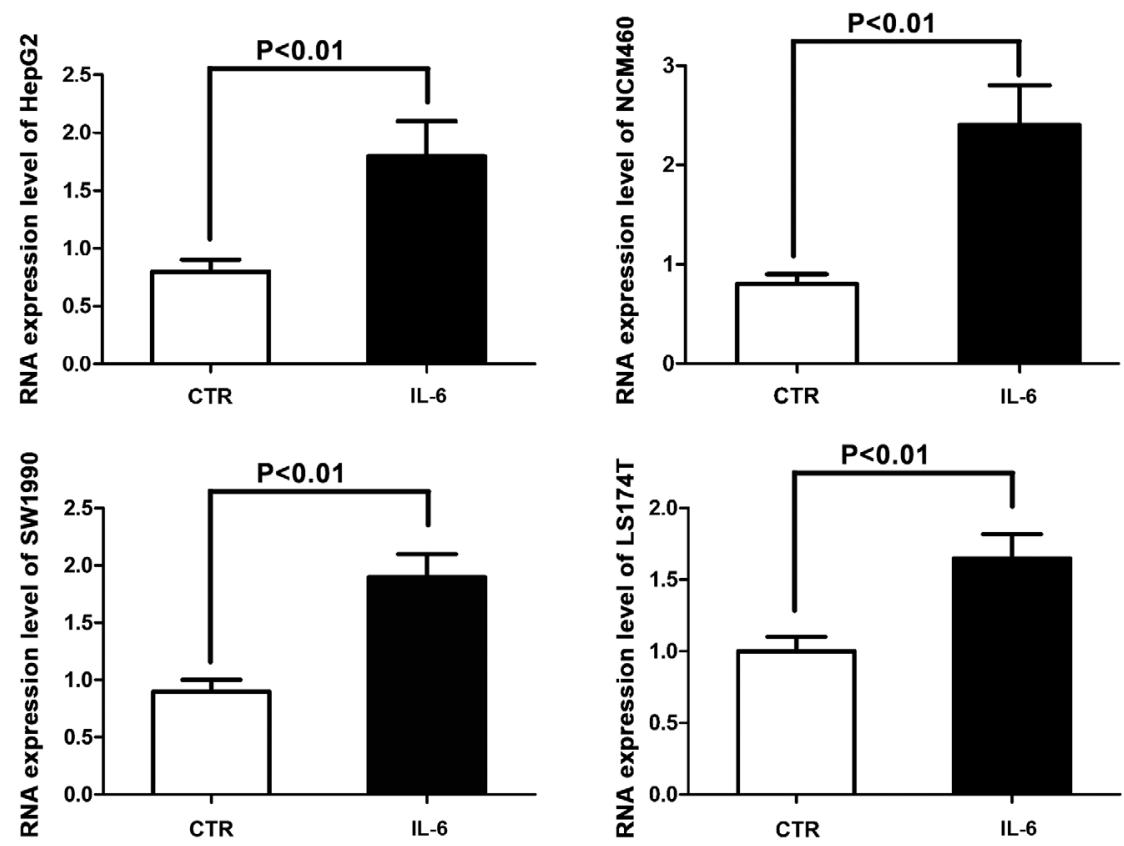

Figure 4. RNA expression levels in the 4 different kinds of cell lines after action of IL-6. Results of real-time PCR demonstrate that the expression levels of $45 \mathrm{~S}$ preRNA in the 4 kinds of cells induced and stimulated by IL- 6 are significantly increased $(\mathrm{P}<0.01)$. IL- 6 plays a regulatory role in the expression of rRNA, $\mathrm{n}=3$. IL-6, interleukin-6; preRNA, preribosomal RNA; rRNA, ribosomal RNA.
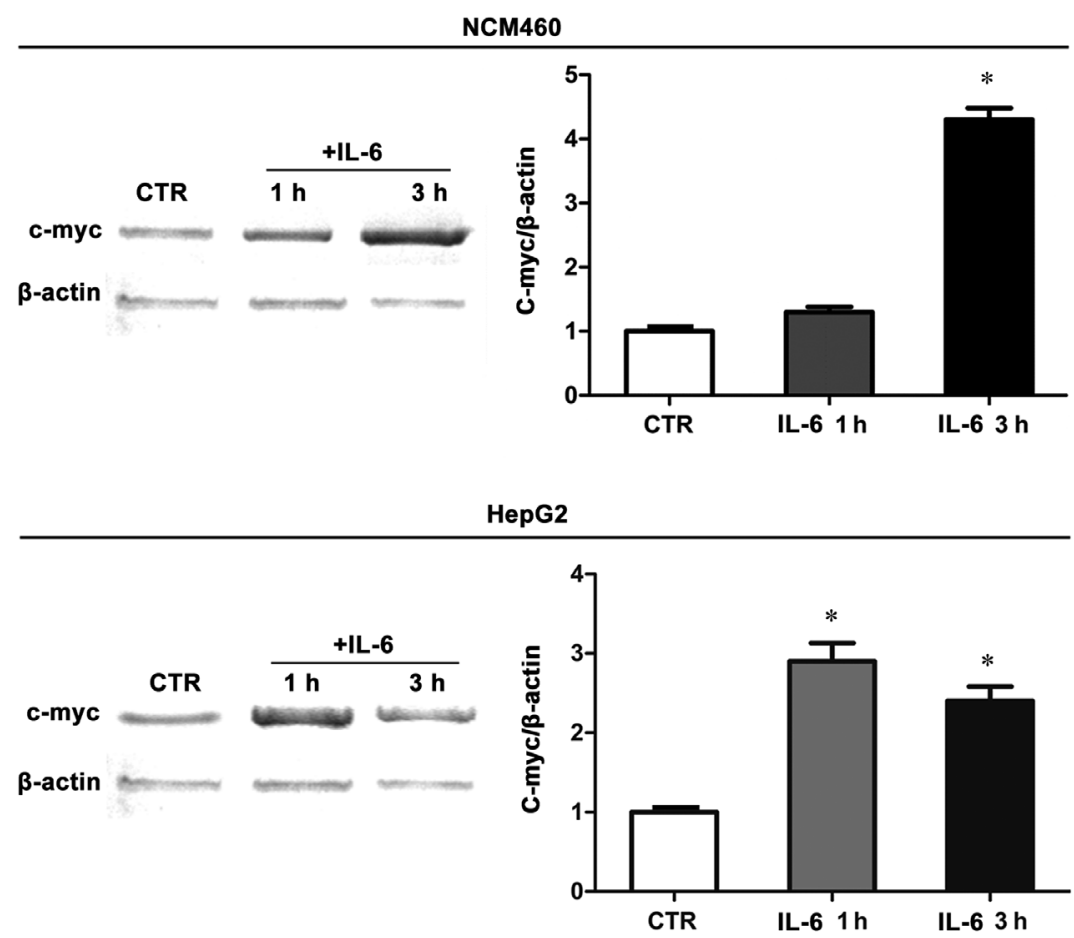

Figure 5. C-myc protein expression in NCM460 and HepG2 cell lines. Analyses of C-myc protein expression in NCM460 and HepG2 cells treated with IL-6 for 1 and $3 \mathrm{~h}$. Results reveal that the C-myc protein expression in NCM460 cells treated with IL-6 for $3 \mathrm{~h}$ is higher than that in NCM460 cells treated with IL-6 for $1 \mathrm{~h}$, and higher than that in blank control group ( $\mathrm{P}<0.01)$. The C-myc protein expression in HepG2 cells treated with IL-6 for 1 and $3 \mathrm{~h}$ are significantly increased compared with that in the blank control group ( $\mathrm{P}<0.01), \mathrm{n}=3$. IL-6, interleukin-6.

in healthy adults $(\mathrm{P}<0.01)$. The level of TNF- $\alpha$ in 25 patients with UC $(723.56 \pm 40.45 \mathrm{ng} / \mathrm{l})$ was also significantly higher than that in healthy adult controls $(448.45 \pm 30.13 \mathrm{ng} / \mathrm{l})$, which was approximately 1.5 -fold higher than that in healthy adults $(\mathrm{P}<0.01)$. The level of IL-10 in 25 patients with UC $(5.68 \pm 2.46 \mathrm{ng} / \mathrm{l})$ was significantly lower than that in healthy adult controls $(11.37 \pm 3.24 \mathrm{ng} / \mathrm{l})$, which was approximately $50 \%$ of that in healthy adults $(\mathrm{P}<0.01)$. The level of IL-4 in 25 patients with UC $(7.01 \pm 1.32 \mathrm{ng} / \mathrm{l})$ was also significantly lower than that in healthy adult controls $(23.56 \pm 2.89 \mathrm{ng} / \mathrm{l})$, which was $<30 \%$ of that in healthy adults $(\mathrm{P}<0.01)$. All the differences were statistically significant (Fig. 1). 
Detection of p53 expression levels in UC patients and healthy adults. The relative expression levels of p53 in peripheral blood of UC patients and healthy adults were detected via quantitative PCR and western blotting. The results revealed that the expression level of p53 in peripheral blood of UC patients $(312.16 \pm 36.34 \mathrm{ng} / \mathrm{l})$ was obviously decreased compared with that in healthy adults $(152.66 \pm 44.42 \mathrm{ng} / \mathrm{l})$ $(\mathrm{P}<0.01)$ (Fig. 2).

Correlation analyses of p53 expression with inflammatory factors. The relative expression level of p53 in peripheral blood of $25 \mathrm{UC}$ patients and the relative expression level of cytokines were analyzed. According to results of linear correlation analyses, only the expression of IL-6 had a significant negative linear correlation with the p53 expression $(\mathrm{r}=-0.437$, $\mathrm{P}<0.001$ ) (Fig. 3).

Analysis of $45 S$ preribosomal RNA (preRNA) expression via $q P C R$. The effects of IL-6 on the ribosomal biosynthesis of 4 kinds of human epithelial cell lines (normal colon epithelial NCM460 cell line, colon cancer LS174T cell line, hepatocellular carcinoma HepG2 cell line and pancreatic cancer SW1990 cell line) were analyzed. The $45 \mathrm{~S}$ preRNA expression was analyzed via real-time PCR to confirm changes in rRNA transcriptional activity in the four kinds of cell lines exposed to IL-6, indicating that IL-6 greatly enhances the transcription of rRNA (Fig. 4).

C-myc protein expression in human epithelial cells. To study the mechanism of IL-6 in stimulating rRNA transcription, whether IL-6 also enhanced the C-myc protein expression in human epithelial cells was investigated. Therefore, NCM460 and HepG 2 cell lines were exposed to IL-6. Western blot analysis revealed that, as evaluated, C-myc protein expression in the two cell lines were significantly increased at $1 \mathrm{~h}$ after IL-6 stimulation. Results showed that IL- 6 activated the transcriptional mechanism and increased the $\mathrm{C}$-myc protein expression under experimental conditions in this study (Fig. 5).

In conclusion, these results strongly suggest that the decrease in p53 expression after treatment with IL-6 is the result of increased C-myc protein translation induced by IL-6, thereby facilitating the $\mathrm{p} 53$ protein digestion.

\section{Discussion}

By studying the expression of p53 protein and related inflammatory factors in UC patients and healthy adults, it was manifested that there was a significant negative correlation between IL-6 and p53 protein expressions. Therefore, its intrinsic mechanism was investigated. It was demonstrated by using human cell lines that IL- 6 stimulated the expression of C-myc. Consequently, the increased C-myc protein expression stimulated the upregulation of rRNA transcription, and enhanced rRNA transcription mediated the p53 degradation $(13,14)$. The decreased p53 protein level was associated with the decline in p53 function, which activated the EMT and increased the invasive potential of cells exposed to IL-6 (15). Downregulation of p53 protein was entirely due to the upregulated ribosomal biosynthesis. Furthermore, it has been reported that the stimulation of IL- 6 on rRNA transcription can be counteracted by C-myc silencing. IL- 6 exposure, as a result of RNA, does not stimulate the polymerase I depletion of p53 protein level in rRNA transcription cells. Evidence suggests that signal transducer and activator of transcription 3 (STAT3) plays a key role in the occurrence of inflammationrelated tumors, such as colon and liver cancer (16). IL-6 is a major activator of STAT3, whose stimulation products increase the transcription of target genes and cell proliferation and survival (17-20). On the other hand, results in this study displayed that the IL-6 effect did not depend on the activation of STAT3 pathway. It was observed that IL-6 induced the expression and transcription of C-myc protein via stimulating C-myc mRNA IRES translation without modifying C-myc mRNA at $1 \mathrm{~h}$ after exposure, which, in fact, is consistent with the reported data on myeloma cell lines (21). Therefore, the possibility that the elevated $\mathrm{C}$-myc protein level may be the result of changes in $\mathrm{C}$-myc mRNA expression and transcription due to activation of STAT3 by IL-6 is ruled out.

The downregulation of p53 expression may be the most important in the transformation process of inflamed tissues and cells. In fact, inflammatory cells, cytokines, chemotactic factors and growth factors that stimulate proliferation and inhibit apoptosis produce reactive oxygen and nitrogen substances, causing DNA oxidative damage, which may no longer be sufficiently repaired as it downregulates the function of p53 (22). As a result, epigenetic changes in oncogenes and other tumor suppressor genes responsible for tumor transformation and progression may be produced. This mechanism may play a role in long-term inflamed tissues, such as human UC colonic mucosa. Actually, the histochemical and immunohistochemical results obtained by using biopsy specimens of colon from UC patients in this study were highly consistent with the results of research conducted in human cell lines. In fact, it has been found that epithelial cells of UC patients were characterized by nucleolus hypertrophy, suggesting the upregulation of rRNA and downregulation of p53 expression $(23,24)$.

\section{Acknowledgements}

Not applicable.

\section{Funding}

This work was supported by Capital Health Development Special Fund (2018-5091).

\section{Availability of data and materials}

The datasets used and/or analyzed during the present study are available from the corresponding author on reasonable request.

\section{Authors' contributions}

HS wrote the manuscript and was responsible for colonoscopy detection. QK and HW helped with immunohistochemical evaluation. HY performed ELISA and LD, YL and RF contributed to isolation of polysome messenger RNA. All authors read and approved the final study. 


\section{Ethics approval and consent to participate}

The study was approved by the Ethics Committee of PLA Army General Hospital (Beijing, China). Patients who participated in this research had complete clinical data. Signed informed consents were obtained from the patients or guardians.

\section{Patient consent for publication}

Not applicable.

\section{Competing interests}

The authors declare that they have no competing interests.

\section{References}

1. Coussens LM and Werb Z: Inflammation and cancer. Nature 420: 860-867, 2002.

2. Mantovani A, Allavena P, Sica A and Balkwill F: Cancer-related inflammation. Nature 454: 436-444, 2008.

3. Lin WW and Karin M: A cytokine-mediated link between innate immunity, inflammation, and cancer. J Clin Invest 117 1175-1183, 2007.

4. Grivennikov SI, Greten FR and Karin M: Immunity, inflammation, and cancer. Cell 140: 883-899, 2010.

5. Nakagawa H, Maeda S, Yoshida H, Tateishi R, Masuzaki R, Ohki T, Hayakawa Y, Kinoshita H, Yamakado M, Kato N, et al: Serum IL-6 levels and the risk for hepatocarcinogenesis in chronic hepatitis $\mathrm{C}$ patients: An analysis based on gender differences. Int J Cancer 125: 2264-2269, 2009.

6. Terzić J, Grivennikov S, Karin E and Karin M: Inflammation and colon cancer. Gastroenterology 138: 2101-2114.e5, 2010.

7. Derenzini M, Trerè D, Pession A, Montanaro L, Sirri V and Ochs RL: Nucleolar function and size in cancer cells. Am J Pathol 152: 1291-1297, 1998.

8. Lennard-Jones JE: Classification of inflammatory bowel disease. Scand J Gastroenterol Suppl 170 (sup170): 2-6, discussion 16-19, 1989.

9. Faccioli S, Chieco P, Gramantieri L, Stecca BA and Bolondi L: Cytometric measurement of cell proliferation in echo-guided biopsies from focal lesions of the liver. Mod Pathol 9: 120-125, 1996.

10. Livak KJ and Schmittgen TD: Analysis of relative gene expression data using real-time quantitative PCR and the 2(-Delta Delta C(T)) method. Methods 25: 402-408, 2001.

11. Canales RD, Luo Y, Willey JC, Austermiller B, Barbacioru CC, Boysen C, Hunkapiller K, Jensen RV, Knight CR, Lee KY, et al: Evaluation of DNA microarray results with quantitative gene expression platforms. Nat Biotechnol 24: 1115-1122, 2006.
12. Kurien BT and Scofield RH: Western blotting. Methods 38: 283-293, 2006

13. Zhang Y and Lu H: Signaling to p53: Ribosomal proteins find their way. Cancer Cell 16: 369-377, 2009.

14. Deisenroth $C$ and Zhang Y: Ribosome biogenesis surveillance: Probing the ribosomal protein-Mdm2-p53 pathway. Oncogene 29: 4253-4260, 2010

15. Montanaro L, Treré D and Derenzini M: Nucleolus, ribosomes, and cancer. Am J Pathol 173: 301-310, 2008.

16. Zhao C, Wang W, Yu W, Jou D, Wang Y, Ma H, Xiao H, Qin H, Zhang C, Lü J, et al: A novel small molecule STAT3 inhibitor, LY5, inhibits cell viability, colony formation, and migration of colon and liver cancer cells. Oncotarget 7: 12917-12926, 2016.

17. Bollrath J, Phesse TJ, von Burstin VA, Putoczki T, Bennecke M, Bateman T, Nebelsiek T, Lundgren-May T, Canli O, Schwitalla S, et al: gp130-mediated Stat 3 activation in enterocytes regulates cell survival and cell-cycle progression during colitis-associated tumorigenesis. Cancer Cell 15: 91-102, 2009.

18. Grivennikov S, Karin E, Terzic J, Mucida D, Yu GY, Vallabhapurapu S, Scheller J, Rose-John S, Cheroutre H, Eckmann L, et al: IL-6 and Stat3 are required for survival of intestinal epithelial cells and development of colitis-associated cancer. Cancer Cell 15: 103-113, 2009.

19. Park EJ, Lee JH, Yu GY, He G, Ali SR, Holzer RG, Österreicher $\mathrm{CH}$, Takahashi $\mathrm{H}$ and Karin M: Dietary and genetic obesity promote liver inflammation and tumorigenesis by enhancing IL-6 and TNF expression. Cell 140: 197-208, 2010.

20. He G and Karin M: NF- $\kappa$ B and STAT3 - key players in liver inflammation and cancer. Cell Res 21: 159-168, 2011.

21. Risques RA, Lai LA, Himmetoglu C, Ebaee A, Li L, Feng Z, Bronner MP, Al-Lahham B, Kowdley KV, Lindor KD, et al: Ulcerative colitis-associated colorectal cancer arises in a field of short telomeres, senescence, and inflammation. Cancer Res 71: 1669-1679, 2011.

22. Yu H, Pardoll D and Jove R: STATs in cancer inflammation and immunity: A leading role for STAT3. Nat Rev Cancer 9: 798-809, 2009.

23. Polyak K and Weinberg RA: Transitions between epithelial and mesenchymal states: Acquisition of malignant and stem cell traits. Nat Rev Cancer 9: 265-273, 2009.

24. Kim S, Keku TO, Martin C, Galanko J, Woosley JT, Schroeder JC, Satia JA, Halabi S and Sandler RS: Circulating levels of inflammatory cytokines and risk of colorectal adenomas. Cancer Res 68: 323-328, 2008.

This work is licensed under a Creative Commons Attribution-NonCommercial-NoDerivatives 4.0 International (CC BY-NC-ND 4.0) License. 